\title{
Cardiac Pathology and Systolic Murmurs in the Elderly
}

\author{
ARIELA POMERANCE
}

From the Department of Morbid Anatomy and Histology, Central Middlesex Hospital, London N.W.10

Systolic murmurs are often noted in elderly patients admitted to hospital (Monroe, 1951). They tend to be dismissed as of no clinical significance and due to aortic sclerosis (Bruns and Van der Hauwaert, 1958); rarely is origin from other valves considered. However, observations during earlier studies on other aspects of cardiovascular pathology in the aged (Pomerance, 1965, 1967) did not seem consistent with these views, and the findings in those patients in whom systolic murmurs had been heard were therefore reviewed.

\section{Material AND METHods}

The hearts previously studied included 173 from patients over 70 years of age, in whom systolic murmurs had been noted on routine clinical examinations. These had been carried out by several clinicians, but in most cases the murmur had been heard by more than one physician and on more than one occasion. All the pathological observations had been made on unfixed hearts by the author; the methods of examination and the valvular abnormalities found have been described and discussed in detail in previous publications (Pomerance, 1965, 1967). Abnormalities of the aortic valve ring and proximal aorta were also included in the present survey.

\section{RESULTS}

The results are set out in the Table.

Mitral valve changes were the only or predominant abnormality in 55 per cent (95) of hearts from all the 173 patients in whom systolic murmurs had been heard. When murmurs described as aortic or basal ejection were excluded, the proportion associated with mitral changes rose to 63 per cent.

The commonest finding was calcification of the mitral valve ring, varying from a small spur with distortion of the overlying posterior cusp to massive nodular calcification of the entire ring with atrial displacement of the whole circumference of the

\footnotetext{
Received January 19, 1968.
}

posterior cusp. This was the only abnormality in 38 per cent of cases with non-aortic (i.e. apical, praecordial, or localization unspecified) murmurs, and in a further 10 per cent it was the predominant lesion, associated with minor degrees of calcification in the aortic cusps. The incidence of other mitral valve abnormalities was much lower. "Ballooning" (i.e. mucoid degeneration) of the posterior cusp, without ring calcification, occurred in 5 per cent of the hearts from patients with non-aortic murmurs, mild non-specific scarring and distortion of the anterior cusp in 5 per cent, excessive nodular thickening ("senile" sclerosis) of the anterior mitral cusp in 4 per cent, and chronic rheumatic type valvular changes involving the mitral valve alone or predominantly in 3 per cent.

Of the 37 cases with murmurs described as aortic or basal ejection in character, 67 per cent (25) did show aortic valve changes, most commonly senile cusp calcification or excessive "wear-and-tear" fibrous thickening; these were the only findings in 22 per cent of this group and were present in association with minor degrees of mitral ring calcification in a further 35 per cent. Rheumatic type changes involving predominantly the aortic valve were present in 3 cases, minor post-inflammatory adhesions without mitral involvement in 1 , and nodular calcification at the upper edge of the aortic ring appeared to be responsible for the murmur in 1 other case.

Aortic valve sclerosis, calcification, or ring calcification were also found in 22 per cent (29) of the cases with non-aortic murmurs, and mitral valve abnormalities were the only or predominant finding in 27 per cent (10) of those with aortic and basal murmurs; 7 hearts showed relatively uncommon miscellaneous changes: 2 with post-inflammatory distortion and thickening confined to the tricuspid valve; 1 each of aneurysms of the sinus of Valsalva, thrombotic endocarditis of anterior mitral cusp, and congenital abnormality of the mitral 
TABLE

FINDINGS IN 173 PATIENTS WITH SYSTOLIC MURMURS

\begin{tabular}{|c|c|c|c|}
\hline \multirow{2}{*}{ Pathological Changes } & \multicolumn{3}{|c|}{ Description of Murmurs } \\
\hline & All Cases & $\begin{array}{c}\text { Aortic or } \\
\text { Basal Ejection }\end{array}$ & Others \\
\hline $\begin{array}{l}\text { Mitral ring calcification-alone } \\
\text { Mitral ring calcification predominant } \\
\text { Chronic rheumatic valvulitis-mitral } \\
\text { Non-specific post-inflammatory changes-mitral } \\
\text { "Ballooning" deformity (mucoid degeneration, mitral) } \\
\text { Excessive nodular thickening ("senile" sclerosis-mitral) }\end{array}$ & $\begin{aligned} 55(32 \%) \\
15(9 \%)) \\
7(4 \%) \\
6(4 \%) \\
7(4 \%) \\
5(3 \%)\end{aligned}$ & $\begin{array}{ll}4 & (11 \%) \\
2 & (5 \%) \\
3 & (8 \%) \\
0 & \\
1 & (3 \%) \\
0 & \end{array}$ & $\begin{aligned} 51 & (38 \%) \\
13 & (10 \%) \\
4 & (3 \%) \\
6 & (5 \%) \\
6 & (5 \%) \\
5 & (4 \%)\end{aligned}$ \\
\hline $\begin{array}{l}\text { Aortic valve calcification/sclerosis-alone } \\
\text { Aortic valve calcification/sclerosis predominant } \\
\text { Calcification of aortic ring or proximal aorta } \\
\text { Chronic rheumatic valvulitis-aortic }\end{array}$ & $\begin{array}{r}25(15 \%) \\
21(12 \%) \\
5(3 \%) \\
3(2 \%)\end{array}$ & $\begin{array}{r}8(22 \%) \\
13(35 \%) \\
1(3 \%) \\
3(8 \%)\end{array}$ & $\begin{array}{cc}17 & (13 \%) \\
8 & (6 \%) \\
4 & (3 \%) \\
0 & \end{array}$ \\
\hline $\begin{array}{l}\text { Other miscellaneous abnormalities } \\
\text { No anatomical deformity }\end{array}$ & $\begin{array}{r}8(5 \%) \\
16(9 \%)\end{array}$ & $\begin{array}{l}2(5 \%) \\
0\end{array}$ & $\begin{array}{l}6(5 \%) \\
16(11 \%)\end{array}$ \\
\hline
\end{tabular}

chordae tendineae were associated with non-aortic murmurs; 1 case with localized marked thickening of the anterior mitral chordae; and the example of isolated post-inflammatory aortic disease, already mentioned, had aortic murmurs.

Only 21 of the 173 hearts had no anatomical valvular abnormalities, but in 5 severe or nodular calcification was present in the proximal aorta. The remaining $16(9 \%)$ were all from patients with nonaortic murmurs. Severe anaemia or hypertension were possible causes of the murmurs in 4 cases, and 7 had extensive old or recent infarcts and therefore possible papillary muscle dysfunction, which DePasquale and Burch (1966) suggested was a common cause of systolic murmurs in the elderly.

\section{Discussion}

Although this was a retrospective study and based on a clinical finding often regarded as unimportant at the time of examination, the results agree well with Howell's (1967) group of 34 cases studied prospectively, and should modify the still widely held belief that most systolic murmurs in old age are of aortic origin (Bruns and Van der Hauwaert, 1958; Bethel and Crow, 1963). Although most of the 37 patients whose murmurs had aortic characteristics did show aortic abnormalities at necropsy, this was so in only one-fifth of the remaining 136 patients, in two-thirds of whom mitral valve abnormalities were the only or predominant finding.

The mechanism of systolic murmur production by aortic cusp or nodular proximal aortic calcification presents no difficulty, neither does well-marked sclerotic cusp thickening. However, lesser degrees of this change, which are a normal finding in almost all adults (Pomerance, 1967), seem an unlikely source of audible haemodynamic disturbances. The role of mitral abnormalities in systolic murmurs is more complex and speculative. Stieglitz (1954) and
Exton-Smith (1955) emphasize that these murmurs should not be considered a phenomenon of normal ageing but that they signify mitral incompetence. They are usually attributed to left ventricular dilatation, but Stieglitz (1954) mentions calcareous mitral changes as a possible cause of apical systolic murmurs, and this was the commonest abnormality found in the present investigation. Distortion and upward displacement of the overlying posterior cusp is frequent in all but mild cases of mitral ring calcification, and resulting incompetence is probably one explanation of the systolic murmurs present in the majority of cases (Korn, DeSanctis, and Sell, 1962; Pomerance, in preparation). In the small proportion where calcification extends inferiorly, without valve distortion, Bruns' (1959) hypothesis of murmurs caused by vortex formation around obstructions offers a convincing explanation. Mitral incompetence in mucoid degeneration has been demonstrated by cine-angiography (Criley et al., 1966; Stannard et al., 1967) resulting from ballooning of the affected cusps into the atrium in systole. In the rheumatic type of mitral incompetence severe post-inflammatory scarring clearly restricts the mobility of the cusps or contracts them to the point where occlusion of the atrioventricular orifice is no longer possible. Lesser degrees of deformity (non-specific post-inflammatory changes) are similarly a potential cause of incompetence, particularly if left ventricular dilatation develops. Malocclusion of the atrioventricular orifice is also a possible explanation for the systolic murmur in "senile" sclerosis, since excessive nodular thickening at the zone of apposition could result in lack of complete contact between the cusps.

With the exception of aortic stenosis, the abnormalities found in the patients with aortic and basal murmurs are of no clinical significance. In contrast, most of those found with non-aortic murmurs are 
associated with increased susceptibility to cardiac failure (Pomerance, 1965), and in the case of mitral ring calcification and mucoid degeneration are potential sites of active endocarditis or spontaneous rupture of chordae tendineae (Read, Thal, and Wendt, 1965). The correct interpretation of systolic murmurs in the elderly is, therefore, of more than academic importance, and a prospective study of possible differentiating features in the elderly is now in progress at this hospital. Difficulties arise because of the high incidence of emphysema (Stieglitz, 1954; Exton-Smith, 1955), and because murmurs due to mitral and aortic abnormalities may mimic each other (Burch and Phillips, 1963). However, because of the different clinical implications, differentiation between these possible sites of origin is worth attempting.

\section{SUMMARY}

The cardiac pathology in 173 patients with systolic murmurs was reviewed. In 37 cases the murmur was considered to be of aortic origin, and anatomical abnormalities were present in the aortic cusps or proximal aorta in 73 per cent of these. In the remaining 136 cases aortic abnormalities were present in only 22 per cent, but there were wellmarked mitral changes in 63 per cent. The commonest finding was mitral ring calcification (47\%), probably causing mitral incompetence through distortion and atrial displacement of overlying cusps. Mucoid degeneration, with incompetence due to systolic ballooning into the atrium, was present in 5 per cent. Non-specific scarring (5\%) and severe nodular sclerosis $(4 \%)$ may prevent full contact of the apposing cusp surfaces and so result in minor degrees of incompetence. No anatomical abnormality was seen in 11 per cent of cases, but anaemia, hypertension, and possible papillary muscle dysfunction were present in all but 5 cases.
Since most systolic murmurs of aortic origin have no clinical significance, while those of mitral origin are associated with an increased incidence of failure and endocarditis, their differentiation is of practical importance.

\section{REFERENCES}

Bethel, C. S., and Crow, E. W. (1963). Heart sounds in the aged. Amer. F. Cardiol., 11, 763.

Bruns, D. L. (1959). A general theory of the causes of murmurs in the cardiovascular system. Amer. F. Med., 27, 360 .

—, and Van der Hauwaert, L. G. (1958). The aortic systolic murmur developing with increasing age. Brit. Heart $\mathcal{F}$., 20, 370.

Burch, G. E., and Phillips, J. H. (1963). Murmurs of aortic stenosis and mitral insufficiency masquerading as one another. Amer. Heart F., 66, 439.

Criley, J. M., Lewis, K. B., Humphries, J. O'N., and Ross, R. S. (1966). Prolapse of the mitral valve; clinical and cine-angiocardiographic findings. Brit. Heart F., 28, 488.

DePasquale, N. P., and Burch, G. E. (1966). The necropsy incidence of gross scars or acute infarction of the papillary muscles of the left ventricle. Amer. F. Cardiol., 17, 169.

Exton-Smith, A. N. (1955). Medical Problems of Old Age, p. 25. Wright, Bristol.

Howell, T. H. (1967). Cardiac murmurs in old age : a clinicopathological study. F. Amer. Geriat. Soc., 15, 509.

Korn, D., DeSanctis, R. W., and Sell, S. (1962). Massive calcification of the mitral annulus. New Engl. $f$. Med., 267, 900 .

Monroe, R. T. (1951). Diseases in Old Age, p. 101. Harvard University Press, Cambridge, Mass.

Pomerance, A. (1965). Pathology of the heart with and without cardiac failure in the aged. Brit. Heart f., 27, 697.

- (1967). Ageing changes in human heart valves. Brit. Heart F., 29, 222.

Read, R. C., Thal, A. P., and Wendt, V. E. (1965). Symptomatic valvular myxomatous transformation. (The floppy valve syndrome.) A possible forme fruste of the Marfan syndrome. Circulation, 32, 897.

Stannard, M., Sloman, J. G., Hare, W. S. C., and Goble, A. J. (1967). Prolapse of the posterior leaflet of the mitral valve: a clinical, familial, and cineangiographic study. Brit. med. F., 3, 71.

Stieglitz, E. J. (1954). Geriatric Medicine, 3rd ed., pp. 362-3. J. P. Lippincott, Philadelphia. 